\title{
PENSAR EL TERRITORIO. PRÁCTICAS INSTITUCIONALES Y MEMORIALES A PARTIR DEL CASO PREDIO QUINTA SERÉ
}

\author{
PENSAR O TERRITÓRIO. PRÁTICAS INSTITUCIONAIS E MEMORIAIS \\ A PARTIR DO CASO QUINTA SERÉ
}
THINKING THE TERRITORY. INSTITUTIONAL AND MEMORIAL PRACTICES AS FROM THE "PREDIO QUINTA SERÉ" CASE

\section{Cora Escolar}

Socióloga. Posgrado en Investigación Social (IDES). Profesora Titular Regular del Dpto. de Geografía e Investigadora. Instituto de Geografía Romualdo Ardissone. Facultad de Filosofía y Letras.

Universidad de Buenos Aires (UBA). Puan 480-CABA (1406). Argentina

E.mail:escolar.cora@gmail.com

\section{Silvina Fabri}

Geógrafa. Becaria Doctoral Universidad de Buenos Aires (UBA). Docente del Departamento de Geografía e Investigadora. Instituto de Geografía Romualdo Ardissone. Facultad de Filosofía y Letras. Universidad de Buenos Aires. Puan 480-CABA (1406). Argentina

E.mail:fabrisilvina@gmail.com

\section{RESUMEN}

En este artículo nos proponemos reflexionar en torno al concepto de territorio como una construcción que se despliega a través del interjuego de prácticas sociales y procesos de subjetivación que hacen e intervienen en los procesos territoriales. Desde los planteos teóricos de la geografía, el análisis institucional y los aportes deleuzianos pretendemos indagar en los alcances del concepto. Precisamente, lo pensaremos a partir de las instancias que intervienen en la hechura institucional, en las aristas de la memoria y las prácticas político-ideológicas que arman y desarman los territorios configurando una cartografía que mapea las irrupciones/acontecimientos productos de las propias prácticas de los sujetos sociales. Intentaremos en relación con estos planteos teóricoepistemológicos examinar el caso del Predio Quinta Seré como un territorio memorial e institucional en constante reescritura.

Palabras clave: Territorio; prácticas memoriales; institución; subjetivación

\section{RESUMO}

Neste artigo, propomos uma reflexão em torno do conceito de território como uma construção que se constitui por meio da interação entre práticas sociais e processos de subjetivação que fazem e intervêm nos processos territoriais. Com base nos aportes teóricos da geografia, da análise institucional e das contribuições deleuzianas pretendemos indagar os alcances do conceito. Precisamente, será pensado a partir das instancias que intervêm no fazer institucional, nas arestas da memória e nas 
práticas político-ideológicas que armam e desarmam os territórios configurando uma cartografia que mapeia as irrupções/acontecimentos produtos das próprias práticas dos sujeitos sociais. Tentaremos, em relação com destes argumentos teóricoepistemológicos, examinar o caso Quinta Seré como um território memorial e institucional em constante reescritura.

Palavras-chave: Território; práticas memoriais; instituição; subjetivação

\section{ABSTRACT}

In this article we propose to reflect on the concept of territory as a construction that unfolds through the interplay of social practices and processes of subjectivation involved in making and taking part on the territorial processes. From the theoretical approaches of geography, institutional analysis and contributions of Deleuze, we intend to investigate on the scope of the concept. Precisely, we think as from the steps involved in the institutional making, on the edges of the memory and the political-ideological practices which arm and disarm territories mapping a cartography that maps the incursions / events. We will try, as from these theoretical and epistemological approaches, to review the case of the "Predio Quinta Seré" like a memorial and institutional territory which is constantly being rewritten.

Keywords: Territory; memorial practices; institution; Subjectivation 


\title{
PENSAR EL TERRITORIO, PUNTOS DE ENTRADA
}

\author{
"El lugar no es diferente de lo que pasa en él; \\ la representación no está en un sujeto"
}

(Deleuze, 2007)

La definición, quizás clásica, en geografía aportada por Robert Sack presupone entender el territorio como una construcción social que delimita un interior, sujeto a control e influencia de un determinado poder hegemónico asociado a un área determinada y a la construcción de un exterior, ajeno a esta influencia. Ahora bien, más allá de las confusiones terminológicas ${ }^{1}$ presentes en las discusiones epistemológicas disciplinarias, principalmente apelamos a la idea de que el territorio siempre está asociado a la construcción de específicos mecanismos de control que involucran un área determinada ${ }^{2}$ y relaciones sociales de poder en donde los límites (que determinan los alcances de este control) cobran relevancia y significancia (BENEDETTI, 2009; RAFFESTIN, 1993; SACK, 1986).

A partir de estas conceptualizaciones del territorio, lo que nos interesa particularmente es tratar de establecer cómo la territorialidad afecta y constituye determinada relación entre el área que delimita - en este caso el Predio Quinta Seré3 - las prácticas sociales y memoriales que allí cobran significancia y, las relaciones de poder, en nuestro caso político-institucionales, para entender cómo y de qué manera la memoria es gestionada y administrada y, cómo estos procesos parecen sostener la subjetivación a partir de la

\footnotetext{
Los conceptos de espacio, lugar y territorio, a lo largo del tiempo han atravesado diversos posicionamientos epistemológicos, y han sido muchas veces utilizados como conceptos intercambiables. Analizar la polémica sobre los alcances teórico-conceptuales de cada uno atraviesa la historia disciplinaria de la geografía en su conjunto. En el caso del espacio pensado en términos de relaciones de poder ha sido un núcleo fuerte de una polémica iniciada por Claval (1976) y que se construyó en torno al terreno ideológico-político, "centrándose en el papel del marxismo y la geografía, soslayando el verdadero problema de buscar si existe una teoría del espacio y definirla” (Sánchez, 1988, p. 27. Resaltados en el original). Las confusiones sobre los alcances conceptuales "vuelve a aparecer entre el uso de territorio y lugar. Ambos tienen niveles similares de concreción (se inscriben en lo que podríamos llamar "el mundo de lo real”), pero se encuentran en niveles escalares diferentes, siendo el lugar más cercano a una escala detallada, mientras que el territorio parecería necesitar de mayor dimensión para ser definido como tal. Podríamos hasta decir que un territorio es un conjunto de lugares. Un elemento que ambos conceptos comparten es su relación con la identificación que de ellos hace o puede llegar a hacer la sociedad, en diferentes escalas" (Reboratti, 2008, p.7).

2 Existe una idea de territorio difundida por la ecología la cual lo define como un área "defendida por un organismo o grupo de organismos similares con el propósito de aparearse, anidar, descansar y alimentarse. La defensa de ese espacio conlleva con frecuencia un comportamiento agresivo hacia los intrusos y un señalamiento de los límites (...). Los humanos, aunque carecen de un nicho ecológico preciso y son capaces de adaptarse a muy diversos espacios, también definen linderos territoriales de los cuales emanan aromas peculiares que identifican a los grupos sociales. Pero no se trata de perfumes químicos sino de efluvios culturales codificados que los llenan de orgullo, aunque en ocasiones resultan repulsivos para otros grupos” (Bartra, 2013, p. 29).

3 El predio Quinta Seré ubicado en el Municipio de Morón, Provincia de Buenos Aires posee 11 ha. En él se encuentra ubicado el Polideportivo Municipal Gorki Grana que funciona allí desde 1985, La Casa de la Memoria y La Vida, sede de la Dirección de Derechos Humanos Municipales que lleva a cabo su tarea desde el $1^{\circ}$ de julio del año 2000 y el Centro de Interpretación e Investigación Arqueológica Espacio Mansión Seré, que con sus características actuales fue inaugurado formalmente en el año 2013. Este espacio cuenta con la puesta en valor de los cimientos de la antigua casona Mansión Seré, incendiada por las fuerzas militares en el año 1978 y finalmente demolida en los inicios del gobierno del Intendente García Silva con la llegada de la democracia. El sitio donde se levantaba la arquitectura de la mansión fue finalmente nivelado y sobre ese terreno se instaló una cancha de fútbol.
} 
inauguración de La Casa de la Memoria y la Vida, sede municipal de la Dirección de Derechos Humanos. El territorio lo pensamos en articulación con la hechura institucional ${ }^{4}$.

Aquí, particularmente, encontramos en la lectura de Anssi Paasi (2003) algunas claves para intentar reflexionar sobre el concepto de territorio y de territorialidad, con ese propósito el autor realiza un recorrido por el planteo de Sack (1986) y, en relación a la posición de este autor, argumenta que

la definición formal de la territorialidad no sólo nos dice lo que es la territorialidad, (...) también sugiere que la territorialidad puede hacer. Este efecto se basa en tres tipos de relaciones entre sí, que están contenidos en la propia definición. En primer lugar, la territorialidad debe implicar una forma de clasificación por zonas, es decir, categorización de las personas y las cosas según la ubicación en el espacio. En segundo lugar, la territorialidad se basa en la comunicación y especialmente la comunicación de las fronteras. En tercer lugar, la territorialidad debe implicar un intento de imponer el control sobre el acceso a la zona y con los objetos en su interior o para los objetos fuera de ella. La territorialidad, como un componente de poder, no sólo es un medio de crear y reproducir el orden social, sino que también es un medio para crear y mantener la mayor parte del contexto geográfico a través del cual experimentamos el mundo y le damos sentido (PAASi, 2003, p. 4. Traducción y resaltados nuestros).

Para Raffestin, el territorio es resultado y producto de los propios actores. Estos hacen el territorio partiendo de esta primera realidad dada que es el espacio.

\begin{abstract}
Hay, pues, un 'juicio' del territorio en virtud del cual se manifiestan todo tipo de relaciones de poder que se traducen en tejidos, redes y centralizaciones cuya permanencia es variable, pero cuya esencia no cambia en cuanto a categorías imprescindibles. El territorio es también un producto 'consumido', o si se prefiere vivido por aquellos que, sin haber participado en su elaboración, lo utilizan como un medio. Es aquí donde todo el problema de la territorialidad irrumpe, permitiendo verificar el carácter simétrico o asimétrico de las relaciones de poder. La territorialidad refleja seguramente el poder que se aproxima a consumir a través de sus productos (1993, p.10. Traducción nuestra. Resaltados en el original).
\end{abstract}

En este sentido, esos productos son variados y variables, se corresponden con procesos territoriales en los que el espacio social y las prácticas sociales son inseparables ${ }^{5}$. La construcción de territorialidades asociadas a la memoria hace necesaria la puesta en discusión del concepto territorio y sus despliegues en prácticas (Escolar, 2005) que traman la territorialidad enlazando diversos niveles institucionales

\footnotetext{
El término se refiere al trabajo reflexivo desarrollado desde el Proyecto Grupos Consolidados UBACyT, Código: 20020130100127BA, "Políticas, instituciones y saberes. La hechura de lugares de memoria (1955-2013)", Acreditado y subsidiado por UBACyT (Secretaría de Ciencia y Técnica de la UBA), 2014-2017 bajo la dirección de la Profesora Cora Escolar. En él, a través de diversas líneas de investigación, se abordan las políticas de la memoria mediante el desarrollo de estrategias de análisis de los modos singulares en que se anudan los dispositivos institucionales de gestión, las prácticas militantes y los saberes que participan en la hechura y constitución de lugares de la memoria.

5 Sack (1986) ha estudiado la historia de la territorialidad humana y llega a la conclusión de que dos transformaciones históricas han visto los mayores cambios en la territorialidad: en primer lugar, el surgimiento de las civilizaciones, y, en segundo lugar, el surgimiento del capitalismo y la modernidad. En el primer caso, la territorialidad se utilizó para definir y controlar a las personas dentro de una sociedad y entre las sociedades, en el segundo, se utilizó la territorialidad para crear imágenes del espacio vaciables, relaciones impersonales, y para ocultar las fuentes de poder" (PAASI, 2003, p. 2-3. Traducción nuestra).
} 
donde se articulan la política, en este caso en particular, las políticas de la memoria, el lugar y las prácticas socioterritoriales.

A partir de estos presupuestos pensamos, siguiendo a Sassen (2003), en la emergencia de nuevos territorios, sujetos y prácticas políticas como mecanismos que se vinculan en una realidad siempre cambiante. Precisamente, reconstruir un pasado ligado al territorio requiere esfuerzos que involucran niveles diversos: simbólicos, narrativos, discursivos, identitarios. Son esos niveles los que se ponen en relación si pensamos en la construcción de un lugar de la memoria y en el propio proceso de institucionalización memorial que requiere de un territorio como ámbito de influencia y como medio de transmisión de sentidos, valores y prácticas. Las selecciones desde este ámbito hacen memoria, la vehiculizan y construyen sus representaciones. Por ello es interesante repensar la relación entre el uso de los soportes y las modalidades que asumen las prácticas memoriales. Teniendo en cuenta que son los

exámenes de archivos, fuentes de la historia y del conocimiento que hablan o emiten imágenes, pero están sordas y ciegas ante sí mismas. Siempre que se intenta una representación del pasado aparece el problema del homúnculo que la contempla. Las fuentes tal vez, incluso, cantan; pero ellas no escuchan su propia melodía: alguien tiene que oírlas e interpretar el canto (Bartra, 2013, p.48).

Creemos que en ese proceso interviene y se construye la subjetivación, volveremos sobre este punto más adelante para plantear conexiones entre los procesos memoriales y las prácticas subjetivas. Sin embargo, ahora nos interesa desplegar conceptualmente precisiones en torno a la propia constitución territorial partiendo de la idea de que los territorios no son marcos congelados donde se produce la vida social sino que más bien los territorios, se hacen, van dando y posibilitando la concreción de significados.

El territorio no es per se, sino que se convierte, se construye en relación con la acción social e individual. Las creencias y acciones involucradas en las prácticas sociales dan significado al territorio, a partir de organizaciones y repartos espaciales, los significados y las representaciones del espacio, los usos y funciones territoriales históricas del espacio y los marcos contingentes y contextuales demarcan un ámbito territorial. El territorio como área de incidencia y la territorialidad como práctica social asociada al ejercicio de un dominio conforman y dimensionan un instrumento eficaz para no cosificar y cristalizar al territorio y, al mismo tiempo, permite despersonalizar al poder. Siguiendo el planteo de Paasi (2003) lo que está en el foco de nuestra reflexión se corresponde con los grados de control, simbólico y espacial de diversas escalas de acción e intervención institucional en un territorio específico. En este sentido, 
en lugar de definir con una frase o dos qué territorios son y cómo funcionan, es más útil entenderlos como procesos sociales, que tienen ciertas características comunes. El proceso a través del cual las unidades territoriales se configuran como parte del sistema socioespacial, (...) estableciendo e identificando la acción y la conciencia social, puede ser pensado como la institucionalización de los territorios (Paasi, 2003, p. 3. Traducción nuestra. Resaltados en el original).

Ese territorio institucional que, en nuestro caso de análisis, involucra tramas memoriales en constante proceso de reterritorialización interviene en los modos en que se construyen las cartografías y mapeos de los procesos en marcha, en ese continuo devenir de la memoria. Como plantea Deleuze y Guatttari (1997) no contamos más que con el lenguaje, incluso para decir lo indecible, habrá que empezar por dar cuenta de la operaciónmapa a partir de aquello ante lo que pretende distanciarse ${ }^{6}$. En ese rodeo, el propio proceso de institucionalización rearma lo límites entre lo que incorpora y lo que deja fuera. Así la memoria encuentra sus bordes y se cartografía en función de determinadas prácticas puntuales que construyen los sujetos habilitados para ser parte.

\section{TERRITORIO, INSTITUCIONES Y SUJETO}

La representación no está en un sujeto, al igual que no existe ningún sujeto que no sea la actividad mental, la cartografía del mundo: memoria, imaginación, percepción, representación, proyección. Toda esta actividad no es del sujeto. Es el sujeto. El problema del sujeto -o más bien el problema de la subjetivación- toma aquí su lugar. ¿Qué es un sujeto? Se pregunta Deleuze. En Deleuze no hay ningún sujeto -a esta palabra le tiene reservada siempre una acogida un poco fría, una cierta sospecha. No hay sujeto sino subjetivación. La subjetividad está determinada como un efecto: es una impresión de reflexión.

El sujeto es la regla de construcción con la cual la colección de ideas (y la emisión de enunciados) se construye un mundo. El proceso de subjetivación es todo uno con el trabajo de esquematización, de construcción conceptual del mundo. Y el mundo es el lugar de la integración psicodinámica de las proyecciones de mentes innumerables.

\footnotetext{
En un interesante trabajo sobre la obra Mil Mesetas, Camilo Ríos (2014) plantea la distinción entre calco y mapa. En el sentido trabajado por él, asociamos al calco con lo instituido, lo hablado, lo dado (Escolar, 2010) pues "el calco es la estabilización de modos de hacer, representación, estructura, garantía, certeza, política, reproducción, aplicación (manual de uso), entrada genética, lógica subyacente, principio explicativo... y la lista seguiría interminablemente: verdad. Es lo que nos permite vivir del modo en que lo hacemos y habitar lo que habitamos, formato de pensamiento y movimiento. Determinación" (2014, p. 2); por el contario el mapa, como su anverso lo pensamos como lo instituyente, lo hablante, la ruptura (Escolar, 2010) eso porque el mapa, "implica simultáneamente un momento previo y uno posterior, un 'entre'. Una operación de experimentación, de apertura, de creación, que implica dar cuenta de lo 'real' constantemente en términos de su acontecer inmediato, in situ. Es lo referente a la operación, la acción, al movimiento y al imperativo de notar y registrar el movimiento real de las cosas cuando está siendo. Un gerundio, si se quiere. El mapa es creación, sorpresa, el mapa es lo que hace hacer. El hacer mismo" (2014, p. 2).
} 
Pero qué es lo dado? (...) es el movimiento, el cambio, sin identidad ni ley (...)Todo lo separable es distinguible, y todo lo distinguible es diferente. Tal es el principio de la diferencia (Deleuze, 2007, p.105-106).

El proceso de subjetivación pasa a través de todos los efectos de desterritorialización y reterritorialización que hacen de la comunicación y dependen de las tecnologías que amplían, complican y canalizan la comunicación. Y la subjetivación depende de las redes que atrapan la singularidad en su relación con los flujos singulares.

Al mismo tiempo, las instituciones se reconfiguran en estos planos yuxtapuestos, en donde los lugares, la memoria y los micropoderes (FOUCAULT, 1992) se dilatan y contraen de manera incesante en el transcurrir y el hacer de una institución (ESCOLAR, 2010). Podemos entender este proceso a través de cuatro abstracciones para dar cuenta de las características y los aspectos que se solapan en esta construcción: la forma territorial, que se asocia con la construcción de los límites en su sentido físico pero también, y este es el segundo punto, la construcción simbólica del territorio, sentido simbólico que involucra elementos dinámicos - discursivamente construidos- elementos fijos - símbolos, banderas, escudos, monumentos-, y prácticas sociales comunes asociadas con el siguiente elemento; la forma institucional, prácticas institucionalizadas como la administración, la política, la economía, la cultura, la comunicación y el sistema escolar a través del cual se producen las fronteras, el simbolismo y su significado y se reproducen; por último, la construcción de la ciudadanía y las narrativas de identidad. Es decir quiénes serán los que estén sujetos a ese poder territorial como prácticas y discursos vinculados o conectados en red a un vector que une pasado-presente-futuro, como una utopía imaginaria de las futuras formas de territorialidad (PAASI, 2003) construyendo y delineando nuevas formas de subjetivación anclada a lo territorial. El caso de la construcción de un lugar de la memoria no escapa a estas configuraciones, en esa construcción se articulan las categorías de universal, particular y singular (Escolar, 2000) abonando formas de subjetivación específicas en relación a las categorías de memoria, ciudadanía, derechos humanos.

Entonces, la relación entre universal, particular y singular, tiene su punto de encuentro a partir de las particularidades. El particular que constituye un universal distinto de otros universales. En ausencia de un universo universal, los "todos" postulados como tales son particulares precarios sometidos sin excepción a las potencialidades alteradoras del devenir.

El "universal" de comienzo se revela como particular. La singularidad cambia su estatuto. Ya nos es singular cada término que compone el universo. No es el hecho de ser uno el que lo vuelve singular. 
Un singular no es "uno sólo" porque uno sólo es uno más: un término previsible, nombrable, discernible bajo las propiedades que estructuran el lenguaje de la situación (o conjunto) en cuestión. Podemos hablar de "singularidades" sólo cuando algo que se presenta hace desfallecer las capacidades clasificatorias de la lengua de la situación: cuando ese algo no se deja contar como un individuo por ninguna de las propiedades discernibles -estructurantes de la situación-.

El término será singular si no pertenece al universo en que irrumpe, su presentación hace tambalear las consistencias previamente instituidas. Así se dirá que un código que regula una situación cualquiera es siempre un particular: está sometida (o suspendida) hasta la sorpresiva irrupción de una singularidad que -destotalizando como particular la legalidad del universo previo- exija un gesto de suplementación (universalización) en nombre de una nueva ley. Las singularidades sólo son un modo de relación con la situación en que irrumpen. Una situación es, en principio, un universo-restringido como todos- que es ciego a la restricción que lo funda.

Siguiendo los planteos de Escolar (2000) y desde la propuesta del análisis institucional ${ }^{7}$ como una corriente de investigación-intervención, la definición del concepto de institución requiere interpretarlo como un lugar de producción y reproducción de las relaciones sociales de producción. "Esto equivale a pensar la institución opuesta a la interpretación durkheimniana de la institución como 'cosa' y por otra parte, a la visión reproduccionista del marxismo" (Escolar, 2000, p. 30. Resaltados en el original).

En su sentido amplio, como cualquier lugar de producción y reproducción de relaciones sociales y en su sentido restringido, como las estructuras materiales y organizativas en que se plasman esas relaciones sociales, la institución anuda tres niveles de análisis: universalidad, particularidad y singularidad. Teniendo en cuenta esta articulación, la institución se nos presenta como una construcción no obvia, pues va más allá de la identificación entre institución y establecimiento (Escolar, 2010). Las fronteras se tornan porosas: lugar de la memoria e institución se configuran como un mojón complejo de la topografía, siempre terra incognita ${ }^{8}$, de la memoria.

\footnotetext{
Los principales exponentes de esta corriente teórica nacida de la coyuntura de mayo francés de 1968, son George Lapassade y René Lourau (Ver Lourau, 1970).

8 El nombre de terra incognita corresponde a los lugares conocidos pero no cartografiados. Desde la Edad Media muchos sitios fueron omitidos de la construcción cartográfica por razones religiosas, políticas o administrativas. Se comportan como sitios fantasmas, difíciles de localizar o precisar (BUADES, 2011).
} 


\title{
LA CONSTRUCCIÓN DEL TERRITORIO Y LA MEMORIA
}

Entonces, regresando al lugar y la subjetivación, vamos a introducir lo impensado en el pensamiento. Es decir, el afuera se pliega y produce al plegarse un adentro coextensivo al afuera, un adentro más profundo que todo el mundo interior, así como el afuera era más lejano que todo el mundo exterior. Podemos llamarlo subjetividad. Lo cual por consiguiente nos comprometería a decir que el pliegue es la sujetivación. El pliegue produce la subjetividad. El ser del sujeto, o la subjetividad, es el plegamiento del afuera.

Volvemos entonces a nuestro punto de partida. Con los modos de subjetivación intervienen las relaciones de poder y siempre es así. Un proceso de subjetivación implica grupos fluidos que son verdaderas generaciones. Siguiendo este planteo nos preguntamos ¿de qué manera analizar, entonces, las relaciones entre lo social en general y las políticas institucionales en particular? (Escolar, 2000). La hechura de una institución presupone, en determina instancia, tratar de establecer en su interior la acción de grupos heterogéneos y en conflicto que pugnan por construir hegemonías y, al mismo tiempo, contra-hegemonías (GRAMSCI, 1970) que presentados, estos últimos, como grupos subalternos tienen incidencia en la configuración institucional. Pensamos entonces que

\begin{abstract}
la hegemonía consiste en una fusión total de objetivos económicos, políticos, intelectuales y morales, efectuada por un grupo fundamental con la alianza de otros grupos a través de la ideología, cuando una ideología logra 'difundirse' entre toda la sociedad y determina no sólo objetivos económicos y políticos unificados, sino también una unidad intelectual y moral. Esta síntesis, cuyo fin será la creación de una voluntad colectiva, puede ser descompuesta analíticamente en dos niveles: el nivel de lo discursivo-retórico y el de las prácticas (políticas) concretas en que dichos discursos están inmersos (Escolar, 2000, p.41).
\end{abstract}

En este punto conflictivo y nodal de la conformación y el funcionamiento de una institución, las tramas tejidas entre el poder y la política, su interrelación y el modo en que se articulan nos resultan insumos para pensar en La Casa de la Memoria y la Vida ${ }^{9}$. En ella, como forma institucional, que rebasa el mero establecimiento, confluyen estas reflexiones acerca de su especificidad.

\section{EL CASO DEL PREDIO QUINTA SERÉ COMO PROCESO DE CONSTRUCCIÓN INSTITUCIONAL. TRAMAS POLÍTICO-MEMORIALES}

En relación a este punto, sobre los inicios del desarrollo del programa memorial, es interesante señalar cómo se solaparon demandas, prácticas einiciativas protoinstitucionales ${ }^{10}$. El funcionamiento institucional de esta Dirección de DDHH articuló los reclamos y

\footnotetext{
9 El funcionamiento institucional de esta Dirección de DDHH tuvo que articular los reclamos y demandas de diversas agrupaciones. Entre ellos mencionamos: Asociación Seré por la Memoria y la Vida, Madres de Plaza de Mayo línea fundadora, abuelas de Plaza de Mayo, H.I.J.O.S. Zona Oeste, Memoria Abierta, Comisión provincial por la Memoria, Familiares de Detenidos y Desaparecidos por cuestiones Políticas, entre otros.

${ }^{10}$ Utilizamos este término para referirnos a las iniciativas que la Asociación Seré y distintos organismos de derechos humanos propusieron al Municipio en relación a la recuperación de los cimientos de la casona utilizada como centro clandestino de de-
} 
demandas de diversas agrupaciones ${ }^{11}$ incorporándolos al Proyecto Mansión Seré ${ }^{12}$. Al mismo tiempo, estos elementos se configuran como insumos y herramientas para construir formas de intervención, administración y gestión de la memoria en el lugar. Como bien señala una integrante de la Asociación Mansión Seré por la Memoria y La Vida ${ }^{13}$ :

desde la asociación tenemos que ver con esto, el primer objetivo que tuvimos fue el de rescatar los cimientos de la casona. Se hizo un proyecto, la asociación hizo un proyecto y se lo presentó al municipio, el municipio lo apoyó y nos relacionó con la capital porque claro esto no era del Municipio de Morón sino que pertenecía a Capital, se firmó un convenio tripartito en el que estaba Jaime por la Asociación, Martín por el municipio e Ibarra por la Capital. Aprobado esto con un georadar que lo trajo Oscar Méndez, otro de los socios, se buscó dónde podían estar los cimientos o si dónde nosotros decíamos que se podían encontrar era que realmente estaban. Después de eso se empezó con las excavaciones haciendo una convocatoria a Antonella Di Bruno ella formó un grupo interdisciplinario con arqueólogos, geólogos, especialistas en patrimonio y alumnos de la facultad entonces se empezó un trabajo impresionante, también con vecinos (...) todo parecía que iba a ir bien pero qué sucedió... trabajaban ad honorem. Nosotros desde la Asociación los únicos ingresos que teníamos eran la cuota de los socios y unas donaciones y después... nada... cuando había actividades acá en el Gorki, poníamos bufet, cuando estaba la Minga también, pero por supuesto todo eso no alcanzaba, lo único que podíamos cubrir era algo de comida para los especialistas, para los estudiantes, que se ocupaban de distintas tareas... a lo sumo eso y los viáticos, bueno esto se fue complicando a medida que avanzaba la excavación. Si llovía al día siguiente se venía todo el trabajo a pique y entonces necesitaban un techo, plata no teníamos así fue como el Municipio en el 2002 incorporó a Antonella Di Bruno y la colocó como encargada de las excavaciones (María Teresa de Sabbatella, palabras en el acto de aniversario $15^{\circ}$ de La Casa de la Memoria y La Vida el día 5 d julio de 2015).

Por otra parte, la creación de La Casa de la Memoria y la Vida, en su gestión administrativa, vincula distintas áreas estratégicas de las políticas públicas municipales. Dedicada a la promoción, preservación y reflexión sobre los derechos humanos posibilita la indagación sobre el pasado reciente (el terrorismo de Estado), la construcción de andamiajes narrativos para abordarlo, el trabajo con niños y jóvenes a partir de diversas actividades que

tención. En las palabras de María Teresa Sabbatella se advierte la incorporación de su propuesta al programa Proyecto Mansión Seré iniciado en el año 2000.

${ }^{11}$ Entre ellos mencionamos: Asociación Seré por la Memoria y la Vida, Madres de Plaza de Mayo línea fundadora, abuelas de Plaza de Mayo, H.I.J.O.S. Zona Oeste, Memoria Abierta, Comisión provincial por la Memoria, Familiares de Detenidos y Desaparecidos por cuestiones Políticas, entre otros.

${ }^{12}$ El Proyecto Mansión Seré iniciado en el año 2002 sentó sus bases sobre el trabajo arqueológico con el fin de "recuperar" los cimientos de la antigua mansión. Este proyecto se inscribió como una iniciativa precursora en el país, en relación a la recuperación de espacios destinados a incentivar la memoria colectiva. A través del rescate del patrimonio tangible e intangible, la conservación de la estructura y la historia del sitio sobre la base de la recopilación de testimonios de diversos actores sociales y la preservación de la memoria histórica sobre los usos del lugar antes, durante y después de su utilización como centro clandestino de detención. Las excavaciones de las estructuras subterráneas (sótano y pozo de agua, por ejemplo) se encuentran abiertas para el desarrollo de visita guiadas y fueron también los primeros pasos para elaborar pruebas y evidencias que sirvieran de base para las investigaciones judiciales. Las materialidades de los vestigios arquitectónicos del centro clandestino de detención Atila cobran una nueva significación asociado a la política de la recuperación del pasado reciente.

${ }^{13}$ La Asociación Civil Mansión Seré se constituye como tal el 21 de noviembre de 2000. Los integrantes que la componen fueron modificándose con el paso del tiempo pero desde un principio existió una interesante diversidad: "desde estudiantes, trabajadores y profesionales, amas de casa, científicos y jubilados. Al principio, según los mismos integrantes, la estructura era aún más heterogénea y había mucha gente del barrio. El primer presidente fue Jaime Stemberg (2000-2002), luego Odilia Casella (2002-2006), Rosa Resnicoff (2006) y Delicia Córdoba de Mompardo (2010-20111)" (DDHH, 2012, p. 108) 
involucran debates, reflexiones y posicionamientos en torno a los DDHH y a la construcción de una ciudadanía participativa, activa y comprometida con ellos a partir del desarrollo de talleres desde el área educativa. Al mismo tiempo también incorpora políticas públicas correspondientes al área de cultura y de deportes municipales ya que, recordemos, en este predio se encuentra funcionando el Polideportivo Gorki Grana.

Hay tres áreas en esta dirección. Una es el área de comunicación, está el área pedagógica, de educación... y el área de investigación que es la que tiene que ver exclusivamente con lo acontecido en la historia reciente y trabaja justamente la oficina está en el EMS. Entonces, si bien las tres áreas se articulan constantemente bajo una dirección para que todas las actividades que se desarrollan tengan un mismo eje. Acá hay tres ejes que maneja la dirección que tienen que ver con investigación, con promoción y con asesoramiento; atendemos casos de violencia institucional. (...) Tenemos una relación constante con el Comité contra la tortura [y con] otras dependencias también municipales donde existe el trabajo de abogados que asesoran, dan una guía a estas personas porque el municipio no patrocina pero sí hace un asesoramiento jurídico en este caso a los familiares y a las personas que están detenidas (Entrevista realizada a Hermann Von Schmellin, 20 de mayo de 2014).

A partir de estas múltiples actividades nos interesa resaltar la labor que trasciende lo meramente memorial con implicancias en múltiples áreas a partir de las tareas desarrolladas desde la Dirección de DDHH. Este es un punto interesante para reflexionar en torno a la conformación y al funcionamiento de esta institución, en donde las tramas burocráticoadministrativas y políticas establecen el modo de interrelación y articulación con otras esferas de la política pública. Al mismo tiempo, pensar en La Casa de la Memoria y la Vida como una institución a partir de sus tareas y actividades más allá de la memoria sobre el pasado reciente nos permite indagar en la forma institucional como anudamiento de múltiples escalas de acción y gestión para entender que la institución rebasa el mero establecimiento físico (Escolar, 2008 y Escolar y Palacios, 2010).

Institucional y territorialmente, la forma en que se entretejen esos significados políticos asociados a las distintas escalas de acción de los programas memoriales nos enfrenta con el concepto de territorio, interpretado aquí como resultado de un complejo proceso de apropiación del espacio, de significación y como condensador de imágenes representativas, enfatizadas y puestas en acción a partir de la implementación de una política pública de la memoria. En este sentido, siguiendo a Escolar (1995), podemos precisar que el discurso político producido en regímenes democráticos y representativos recurre a argumentos que van más allá de la esfera o el ámbito de acción meramente jurídico e interrelaciona y complementa campos discursivos y herramientas simbólicas que hacen y construye diversos territorios, subjetividades e identidades impactando en los, muchas veces sucesivos y yuxtapuestos, procesos de territorialización, desterritorialización y reterritorialización (HAESBAERT, 2011). 
De esta manera, la práctica social que se institucionaliza mediante prácticas territoriales se corresponde con lo que podemos denominar procesos de conmemoración/ rememoración, en donde la memoria social, sus múltiples dimensiones y significados, sus usos, su gestión y su proyección político-institucional ha tenido especial relevancia en el campo académico, en los medios de comunicación y en el campo de las políticas de gobierno (GARCÍA ÁLVAREZ, 2009). Esto nos lleva a pensar estas prácticas particulares atravesadas por regímenes y mecanismos de visibilidad específicos los cuales se plantean y dirimen en la construcción de diversas manifestaciones y estrategias en la esfera pública a la hora de dar marco a las prácticas memoriales que se configuran como territorios múltiples o multiterritoriales (HAESBAERT, 2013).

\section{POLÍTICAS PÚBLICAS Y TERRITORIO}

A través del análisis institucional podemos indagar en el entramado de una política pública de la memoria a partir de su gestión, implementación y administración en el marco de las actividades desarrolladas desde La Casa de La Memoria y La Vida, así como también de las interrelaciones con el Espacio Mansión Seré (EMS) ${ }^{14}$. Sostenemos que las políticas públicas de la memoria, de manera transversal, coadyuvan a construir un lugar de la memoria como dispositivo, en el sentido deleuziano del término, produciendo una institucionalización de la práctica memorial (Escolar, 2009). Al mismo tiempo, podemos problematizar el comportamiento de los micropoderes en pugna dentro de un mismo ámbito de gestión administrativa y de las condiciones de posibilidad para la concreción y ejecución de políticas datadas y situadas históricamente (ESCOLAR, 2009) donde se enmarcan, producen y visibilizan determinadas prácticas sociales, políticas, educativas y culturales presentes en los trabajos memoriales realizadas en el predio Quinta Seré.

En suma, pensamos en trazar conexiones entre esa forma institucional y sus prácticas memoriales materializadas en el espacio urbano para, en un segundo momento, indagar en torno a los mecanismos de implementación gubernamental de la política y reflexionar acerca de cómo se configuran, mediante un artilugio operativo y administrativo, la construcción de

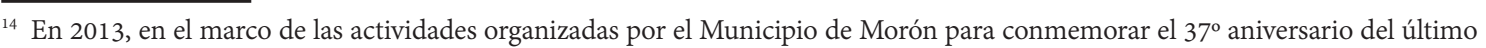
Golpe de Estado, el intendente de Morón, Lic. Lucas Ghi, junto a la presidenta de la Nación, Dra. Cristina Fernández de Kirchner, y el ex intendente Martín Sabbatella, inauguraron el Espacio Mansión Seré Centro de Investigación e Interpretación de Nuestra Historia Reciente. El mismo es resultado del proyecto arqueológico y antropológico de recuperación y preservación del lugar donde funcionó el centro clandestino de detención y torturas conocido como Atila durante la última dictadura. El proyecto contempló la creación de un laboratorio de $161 \mathrm{~m} 2$ donde funciona un centro de análisis de investigación y depósitos arqueológicos, la construcción de pasarelas que permiten recorrer y observar los cimientos de la vieja casa, un patio de la memoria y otras áreas de observación. El Espacio Mansión Seré constituye el conjunto de referencias nacionales y regionales en la tarea de recuperación de sitios vinculados a los sucesos ocurridos en procesos de dictaduras y busca favorecer la reflexión sobre el significado de "Mansión Seré" como experiencia posible, como experiencia que se multiplica por miles a lo largo y ancho de nuestro continente. (En: http:// www.moron.gov.ar/autoridades/acciones-de-gobierno/derechos-humanos/casa-de-la-memoria-y-la-vida/ )
} 
la institución memorial en un espacio público a partir del análisis de sus actividades en curso. En primer lugar, entendemos al poder en el sentido planteado por Foucault

el poder está en todas partes; no es que lo englobe todo, sino que viene de todas partes... no es una intuición y no es una estructura, no es cierta potencia de la que algunos estarían dotados: es el nombre que se presta a una situación estratégica compleja en una sociedad dada" (1999, p. 113. Resaltados nuestros).

Podríamos afirmar, siguiendo este planteo, que el poder está construido como una estrategia que se ejerce, pero, al mismo tiempo, el poder - o mejor aún, los múltiples poderes - se desarrollan en su microfísica, la cual no se corresponde con una continuidad lineal, de arriba hacia abajo ni viceversa, sino que en su práctica existen porosidades. El poder está constituido por transversalidades, por líneas de quiebre y ruptura y, en este sentido, se construye en su propia dispositividad.

En segundo lugar, pensamos la política de memoria a partir de la gestión institucional, es por ello que se presenta como una política de escala en donde operan los calificadores espaciales local, regional, nacional (Cox, 1998). Estos niveles involucran una serie de estrategias escalares puestas en relación. La política se encuentra anclada territorialmente, pero al mismo tiempo encuentra puntos de fuga en sus fronteras porosas, se enlaza de manera constante con otros ámbitos políticos y territoriales. Así,

\begin{abstract}
al cambiar de nivel, el enfoque es otro. Lo 'nacional' presupone un espacio amplio. Aunque su territorio está también físicamente determinado, sus límites son fijos, su extensión es más dilatada. A él se suma además una historicidad, dimensión a veces olvidada cuando nos referimos a lo 'local' (por eso, la tendencia a identificarlo con la tradición, la conservación de las costumbres). (...) Transita el camino de la turbulencia histórica, se modela de acuerdo con los intereses de sus instituciones, sus luchas, su visión del pasado, su política de construcción del presente. Proceso largo, que presupone la ocupación de un área geográfica y la invención de una conciencia colectiva compartida por sus ciudadanos. En relación con lo 'local', lo 'nacional' se impone por su unidad. Existe una cultura nacional, aun cuando sabemos que ella se realiza de manera diferenciada en los diversos contextos (conflicto que se expresa en contradicciones) (ORTIZ, 1998, p.31).
\end{abstract}

De esta manera, la política localizada se convierte en una política de territorios que se asume como una práctica particular sobre determinado espacio de acción. Se trata de la dialéctica de estos tres momentos universalidad, particularidad y singularidad que hacen funcionales a tres conceptos que introdujimos: instituido, instituyente e institucionalización. Por ejemplo: con el concepto de territorio, pensamos que toda forma social se crea y se transforma en este proceso de territorialización. No hay positividad en lo social y en lo social-histórico, y es por eso que se pueden analizar las formas socio-territoriales-históricas.

El análisis de estos niveles permite dar precisiones sobre el territorio como un proceso de invención históricamente datada, involucra el comportamiento dinámico de las células 
administrativas que dan cuerpo al Estado y al mismo tiempo posibilitan pensar en la instauración de un espacio pretendidamente homogéneo al cual es posible administrar (ALLIÉS, 1980) pero que se sustenta en una territorialidad dilatada (SASSEN, 1991).

De esta manera mapear conceptualmente estas multiplicidades territoriales involucran pensar en capas temáticas que permitan visibilizar prácticas políticas y memoriales de acción escalar diversa. Así, en nuestro caso de análisis las políticas públicas de la memoria están sustentadas por un triple andamiaje escalar (nacional, provincial y municipal) la institución se encuentra conectada territorialmente a través de una política que atraviesa transversalmente esos ámbitos de acción puestos en articulación.

En ese sentido, la memoria es gestionada en torno a procesos de institucionalización en el marco de una política de escala amplia (una escala nacional de políticas de la memoria) y operacionalizada a partir de decisiones político-administrativas tomadas desde la escala de acción institucional (en este caso municipal). En esta confluencia de escalas, de prácticas de participación, modos de intervención en el predio, promoción de intereses y de contenidos en la elaboración de talleres para trabajar con temáticas sobre derechos humanos se conforman contextos socio-espaciales particulares en el predio.

El trabajo memorial institucionalmente inscripto a través del Proyecto Mansión Seré y de las tareas desarrolladas desde La Casa de la Memoria y La Vida ${ }^{15}$ y el Espacio Mansión Seré traza condiciones de posibilidad para un hacer memorial a través de actividades en torno a la historia reciente y a la reflexión sobre los derechos humanos en su conjunto. Podemos sostener que el lugar de memoria no está construido sólo por su condición material de espacio físico sino que en él se entrelazan y articulan, a partir de la implementación de una política pública, la reactivación de una memoria en relación al pasado reciente traumático, la conmemoración de las víctimas y el pedido de justicia; ejes que cobran vital importancia en las fechas conmemorativas y que permiten delimitar los ámbitos de referencia territorial en el espacio urbano. El hacer memorial mediante un hacer institucional hace territorio y lo redefine de manera constante.

Las políticas de intervención y construcción de la memoria colectiva en el espacio urbano, ya sean de carácter público como de carácter privado, nos sirven de referencia para intentar mostrar cómo dichas políticas intervienen en la conformación de los sentidos de la memoria, dibujando los contornos de una memoria colectiva y social y, al mismo tiempo, construyendo procesos de subjetivación.

\footnotetext{
${ }^{15}$ En la década del '90 como símbolo del uso indiscriminado de los recursos públicos, el entonces intendente Juan Carlos Rousselot pasó por alto los controles del Concejo Deliberante y ordenó construir en el Predio Quinta Seré un edificio para realizar reuniones privadas a metros de la ya demolida mansión. En ese edificio funciona actualmente la sede de la DDHH municipales. (http://www.moron.gov.ar/autoridades/acciones-de-gobierno/derechos-humanos/casa-de-la-memoria-y-la-vida/)
} 
La participación de una multiplicidad de sujetos sociales en el armado y el diseño de la política memorial supone una arena de confrontación/negociación en el proceso de institucionalización de la memoria (Escolar, 2010) que habilita la constante reterritorialización de la prácticas desplegadas en la hechura institucional.

\section{TODO ESCAPA AL SUJETO QUE ESCRIBE...}

Hemos tratado de manifestar a través de lo escrito un nuevo imaginario que corresponde al orden del pensamiento. En este debate de ideas la escritura no es el habla pero tampoco es lo escrito, la transcripción. En el fondo, esta travesía a través del lenguaje, difícil, complicada, variada se despliega cubriendo un campo muy vasto de la actualidad científica e intelectual acerca del concepto de territorio.

Todo tiene un sentido, incluso el sinsentido (que tiene por lo menos el sentido segundo de ser un sinsentido). Dicho de otro modo, si queremos resumir lo que hemos desplegado, ya lo aventuramos con nuestro epígrafe inicial citando a Deleuze (2007, p.15), lo que se transmite son formas que pueden llenar de modos diferentes el concepto de territorio.

Cuando decimos esto nos referimos constantemente a la idea de que el territorio es una construcción inscripta a través de la yuxtaposición de prácticas sociales y procesos de subjetivación que hacen e intervienen en los procesos territoriales. Nos esforzarnos en percibir y reexaminar estos planteos múltiples para comprender por medio de qué cadenas de relaciones se construyen el sujeto y objeto de conocimiento y esto parece avizorarse como una tarea en permanente construcción.

\section{REFERÊNCIAS}

1. ALLIĖS, Paul. L 'invention du territoire, Francia: Presses Universitaires de Grenoble, 1980.

2. BARTRA, Roger. Territorios del terror y la otredad, Buenos Aires: Fondo de Cultura Económica, 2013.

3. BENEDETTI, Alejandro. Territorio: concepto integrador de la geografía contemporánea. En: Patricia Souto (coord.) Territorio, lugar, paisaje. Prácticas y conceptos básicos en geografía, Buenos Aires: Ed. De la FFYL, UBA, pp. 11-82, 2011.

4. BUADES, Antonia. Cartografía. Historia de los mapas antiguos. En: http://valdeperrillos.com/ book/export/html/1146, España: Palma de Mayorca, 2011.

5. CLAVAL, Paul. Espacio y poder. México: Fondo de Cultura Económica, 1976.

6. COX, Kevin. Spaces of dependence, spaces of engagement and the politics of scale, or looking for local politics. En: Political Geography, vol. 17, n.1, p. 1-23, 1998. 
7. DELEUZE, Gilles y Félix Guattari. Mil Mesetas. Capitalismo y esquizofrenia, Valencia, España: PRE-TEXTOS, 1997.

8. DELEUZE, Gilles. Empirismo y subjetividad. Gedisa: Barcelona, 2007.

9. ESCOLAR, Cora (comp.). Topografías de la investigación. Métodos, espacios y prácticas profesionales, Buenos Aires: Eudeba, 2000.

10. ESCOLAR, Cora. Territorios de la interacción: los caminos del exilio. En: Revista Espacios de crítica y producción, № 33, Buenos Aires: Publicación de la Facultad de Filosofía y LetrasUBA, noviembre-diciembre, 2005.

11. ESCOLAR, Cora. Del compromiso político a la lucha por los derechos. Los Observatorios de Derechos Humanos como enclave territorial. En: Geousp - Espaço e Tempo. Revista da Pósgraduação em Geografia, No 24, p. 182-187. Brasil, 2008. Disponible em: www.geografia.fflch. usp.br/publicacoes/geousp/Geousp24/Intercambio_Cora_Escolar.pdf

12. ESCOLAR, Cora. Políticas Públicas y Memoria. Los observatorios de derechos humanos. En: Revista Internacional de Ciencias Sociales y Humanidades (SOCIOTAM), Vol. XIX, No 2, México: Universidad Autónoma de Tamaulipas, p. 35-50, 2009.

13. ESCOLAR, Cora. Institución, Implicación, Intervención. Revisando y revisitando las categorías del Análisis Institucional. En: ACCIONES, Investigaciones Sociales: Universidad de Zaragoza, p. 235-250, 2010 .

14. ESCOLAR, Cora y Cecilia Palacios. La producción del espacio urbano y la dimensión espacial de las prácticas institucionales. El caso del Espacio para La Memoria y Para la Promoción y defensa de los Derechos Humanos (Ex ESMA). En: XI Coloquio internacional de Geocrítica, Buenos Aires, p. 1-12, 2010. Disponible en: www.eventosfilo.uba.ar/geocritica

15. ESCOLAR, Marcelo. Territorios de representación y territorios representados. La mediación geográfica de la identidad y la soberanía política Nacional-Estatal. En: V Reunion de antopologia do (merco) sul, Tramandaí/Rs, del 12 al 15 de septiembre, pp. 1- 11, 1995.

16. FOUCAULT, Michel. Microfísica del poder, Madrid: Ed. La Piqueta, 1992.

17. FOUCAULT, Michel. Historia de la sexualidad. La voluntad de saber. Tomo I, Madrid, España: Siglo XXI, 1999.

18. GARCÍA ÁLVAREZ, Jacobo. Lugares, paisajes y políticas de memoria: Una lectura geográfica. En: Boletín de la A.G.E., No 5. España, pp. 175-202, 2009.

19. GRAMSCI, Antonio. Escritos políticos (1917-1933), Buenos Aires: Cuadernos del Pasado y Presente, 1970.

20. HAESBAERT, Rogério. El mito de la desterritorialización. Del "fin de los territorios" a la multiterritorialidad, México: Siglo XXI, 2011.

21. HAESBAERT, Rogério. Del mito de la desterritorialización. A la multiterritorialidad. En: Cultura y representaciones sociales. Un espacio para el diálogo transdisciplinario, Año 8, No 15, pp. 9-42, 2013. En http://www.revistas.unam.mx/index.php/crs/article/view/41590 
22. LOURAU, René. Análisis institucional y cuestión política. En: R. Lourau et al: Análisis institucional y socioanálisis, México: Ed. Nueva Imagen, 1979.

23. ORTIZ, Renato. Otro territorio. Ensayos sobre el mundo contemporáneo. Santa Fe de Bogotá, Colombia: Ed. Convenio Andrés Bello, 1998.

24. PAASI, Anssi. Territory in: Agnew, Jhon, K. Mitchell y G. Toal (eds.): A companion to political geography, Oxford: Blackwell Publishers, 2003.

25. REBORATTI, Carlos. El territorio rural: ¿actor o escenario? En: V Jornadas de Investigación y Debate. Trabajo, propiedad y tecnología en la Argentina rural del siglo XX, Bernal: Universidad Nacional de Quilmes, 2008. Disponible en: www.unq.edu.ar/servlet/ ShowAttach?idAttach $=13767$.

26. RAFFESTIN, Claude. Por uma geografia do poder, San Pablo: Atica, 1993.

27. SACK, Robert. Human Territoriality. Its theory and history, Cambridge: Cambridge University Press, 1986.

28. RÍOS, Camilo. Diálogos deleuzianos. Producción de inconsciente: mapear la vida. En: http:// anarquiacoronada.blogspot.com.ar/2014/07/dialogos-deleuzianos-produccion-de.html, 2014.

29. SÁNCHEZ, Joan-Eugení. La geografía y el espacio social del poder. Barcelona, España: Ed. Los libros de la frontera, 1988.

30. SASSEN, Saskia. La ciudad global. Nueva York, Londres, Tokio. Buenos Aires: Ed. Eudeba, 1991.

31. SASSEN, Saskia. Contrageografías de la globalización.Género y ciudadanía en los circuitos transfronterizos, Madrid. España: Ed. Traficantes de sueños, 2003.

\section{FUENTES}

32. Dirección de Derechos Humanos (2012): Casa de la Memoria y La Vida. Su historia y sus protagonistas, Municipio de Morón, Buenos Aires.

33. Entrevista a Hermann Von Schmellin, responsable del área de difusión en La Casa de La Memoria y la vida, realizada el 20 de mayo de 2014.

Artigo recebido em 10 de dezembro de 2015.

Artigo aceito em 27 de dezembro de 2015. 